\title{
Neutropenia and Cancer Patients
}

\section{Bassam Abdul Rasool Hassan*}

Clinical Pharmacy Discipline, School of Pharmaceutical Sciences, University of Sains Malaysia, 11800, Minden, Penang, Malaysia

\section{Introduction}

Neutropenia is defined as a decrease in the absolute number of neutrophils in the blood. Clinically, neutropenia is defined as a decrease in the absolute neutrophil count (ANC) of more than two standard deviations below the normal range. So the patient is considered as neutropenic when the ANC is lower than the normal level which is 1500 cell/ $\mu \mathrm{l}[1]$.

So generally this dangerous condition called neutropenia will occur when the neutrophils cells counts is lower than the normal count which is $1500 \mathrm{cell} / \mu \mathrm{l}$ [1-5]. Even so when the neutrophil count is more than $1000 \mathrm{cell} / \mu \mathrm{l}$ there will still be normal protection against infection. When the level of neutrophils falls to $500-1000$ cell/ $\mu$ it is classified as mild neutropenia and moderate neutropenia happened when the count falls between 200-500 cell/ $\mu$ l [1-3]. When the neutrophil count falls lower than $200 \mathrm{cell} / \mu \mathrm{l}$; it is considered as a very serious condition that requires the patient to be admitted to the hospital and treated with antibiotics [2-3]. It has been reported that the normal neutrophil count in the white man is $1500 \mathrm{cell} / \mu \mathrm{l}$ while in the black man the normal is lower (i.e., $1200 \mathrm{cell} / \mu \mathrm{l})$ [5].

While febrile neutropenia (i.e., when patient developed fever) is mostly associated with chemotherapy regimen it may also occur after irradiation of most parts of the bone marrow. Here the term febrile neutropenia is usually used to describe the occurrence of neutropenia and fever that is when the body temperature is $\geq 38.3^{\circ} \mathrm{C}$ or oral temperature $\geq 38^{\circ} \mathrm{C}$ for more than one hour and the neutrophil count is $\leq 500 \mathrm{cell} / \mu \mathrm{l}$ or it will reduced to $\leq 500 \mathrm{cell} / \mu \mathrm{l}$ within the next 48 hours $[1,6-8]$.

\section{Adverse Effect of Neutropenia}

The incidence of neutropenia has been shown to have negative effects on the patient. The percentage of cancer patients who did not receive their total amount of chemotherapy drug doses has increased. Fifty percent (50\%) of these cancer patients received less than $85 \%$ of the actual doses because of neutropenia. Breast cancer seems to be the type of cancer most associated with neutropenia complication. About $25 \%$ of the breast cancer patients suffered from neutropenia resulting in reduction of their chemotherapy doses [8].

However, there was no accurate number or percentage of neutropenia prevalence or occurrence as a side effect of chemotherapy was reported $[9,10]$.

\section{Neutropenia Causes}

Factors that play a major role in causing neutropenia are demographic factors, hematological disorder, autoimmune diseases, infection, drugs reactions and chemotherapy or radiotherapy.

Neutrophils production decrease in the elderly since they have a lower ability to produce mature neutrophils than younger people. Besides that the neutrophil count in white man is higher than that in the black man. Also neutropenia incidence seems to be more in women than men $[1,2,5]$.

Hematological diseases like leukemia, myelodysplastic syndrome, Hodgkin's and non-Hodgkin's diseases and multiple myloma have been shown to cause neutropenia [1]. In these hematological diseases severe destruction of bone marrow leads to destruction of stem cells. This will result in the prevention or decrease in neutrophils production and thus causing neutropenia [1]. Also there is an effect on red blood cells (RBC) and platelets production which will lead to severe anemia and thrombocytopenia. Usually the patient will suffer from fever $\geq$ $38.5^{\circ} \mathrm{C}$ as well as gingivitis, bleeding, stomatitis, bone chills and patient might also collapse [11].

Neutropenia has also been associated with autoimmune disease like systemic lupus erythromatosis (SLE). The neutropenia in SLE is usually mild and the patient may not suffer from serious bacterial infection. However patients with SjÖren syndrome and rheumatoid arthritis may have severe neutropenia so they are at higher risk of bacterial or fungal infection. Neutropenia may also occur with aplastic anemia [1].

Many drugs such as diuretics, chlorpromazine, and allopurinol have been shown to cause neutropenia. Two mechanisms have been suggested to cause neutropenia. Firstly, the drugs produce dose dependant toxicity on cell production, protein synthesis, bone marrow and cell survival. Secondly, the mechanism may involve the drug inducing immunological reactions. For an example the binding of drugs with the surface of the neutrophil cell will lead to cell destruction and cause production of neutropenia. These two mechanisms are not always seen but happen only in a small percentage of the patients. Also these two mechanisms need a long duration of use that is from starting the administration of the drug to the appearance of neutropenia.

While in the case of solid tumor as the focused of this present study, most of the patients have normal neutrophils but due to the intensive chemotherapeutics drugs and regimens neutropenia developed [12].

Neutropenia has been seen to be mostly associated with cancer chemotherapy and radiotherapy. These chemotherapeutic drugs will affect the production of folic acid as well as the synthesis of DNA, RNA and protein by acting as anti metabolite which will lead to bone marrow destruction $[1-3,5,11]$. Bone marrow destruction will then lead to a

*Corresponding author: Bassam abdul rasool Hassan, Clinical Pharmacy Discipline School of Pharmaceutical Sciences, University of Sains Malaysia, 11800, Minden Penang, Malaysia, Tel: (+6)016-423-0950; E-mail: bassamsunny@yahoo.com

Received August 05, 2012; Accepted August 07, 2012; Published August 09, 2012

Citation: Rasool Hassan BA (2012) Neutropenia and Cancer Patients. Pharmaceut Anal Acta 3:e115. doi:10.4172/2153-2435.1000e115

Copyright: (C) 2012 Rasool Hassan BA. This is an open-access article distributed under the terms of the Creative Commons Attribution License, which permits unrestricted use, distribution, and reproduction in any medium, provided the original author and source are credited. 
decrease in neutrophil cell production. Due to this, the chemotherapy and radiotherapy are considered as the main causes for neutropenia or febrile neutropenia (i.e., neutropenia when associated with fever and $\mathrm{ANC} \leq 500 \mathrm{cell} / \mu \mathrm{l})$. Also these chemotherapeutic drugs will kill and suppress every cell that is highly dividing or actively growing like cancer cell but unfortunately they also have an effect on the blood cells especially bone cells and neutrophil cells [13]. Examples of chemotherapeutic drugs which are highly associated with neutropenia are actinomycin, asparaginase, cytarabine, busulfan, cisplatin, daunorubicin, etoposide, fluorouracil, ifosfamide and methotrexate $[1,5,14]$.

\section{Conclusion}

Therefore it is an obligate matter for the doctors and clinicians who works within cancer treatment to focus on this major side effect by doing more research and studies in order to develop a treatment guideline which can help to overcome or prevent or palliate this side effect.

\section{References}

1. Dale CD (2005) Life sciences. 13: 147-153.

2. Walker R, Edwards C (2003) Laboratory data. Clinical Pharmacy \& Therapeutics. New York: Churchill Livingstone, 47-65.

3. Frey R, Granger J (2002) Neutropenia. The Gale Encyclopedia of Cancer. Detroit, Gale Group.

4. Frey RJ (1999) Neutropenia. The Gale Encyclopedia of Medicine. Farmington
Hills, Gale Research, An International Thomson Company.

5. Linker CA (2000) Blood. Current Medical Diagnosis and Treatment. New York, Appleton \& Lange.

6. Bledsoe BE, Kufs D, Soltis CA (2005) Hematology. Paramedic Care / Principles and Practice New Jersey, Pearson Prentice Hall.

7. Al-Ahwal M (2005) Pattern of febrile neutropenia in solid tumors - A hospital based study. Pak J Med Sci 21: 249-252.

8. Lyman GH (2006) Risks and consequences of chemotherapy-induced neutropenia Clin Cornerstone 5: S12-S18.

9. Neutropenia Association Inc. (1993) Neutropenia, causes, consequences and care. What is Neutropenia. Canada.

10. European Parliament (1999) Decision no 1295/1999/ec of the european parliament and of the council of 29 april 1999 adopting a programme of community action on rare diseases within the framework for action in the field of public health (1999 to 2003). Official Journal of The European Communities 155: $1-5$.

11. Verstraete M, Vrhaeghe R, Peerlinck K, Boogaerts MA (1987) Haematological Disorders. AVery's Drug Treatment. Auckland, Adis Press.

12. Rolston KVI (2001) Infections in Patients with Solid Tumors. Text Book of Febrile Neutropenia. London Martin Dunitz, Ltd.

13. Fortner BV, Schwartzberg L, Tauer K, Houts AC, Hackett J, et al. (2005) Impact of chemotherapy-induced neutropenia on quality of life: a prospective pilot investigation. Support Care Cancer 13: 522-528.

14. Kimble-Koda MA, Young LY, Kardjan WA, Guglielmo BJ (2002) Infections in Neutropenic Patients. Hand Book of Applied Therapeutics Philadelphia Lippincot Williams \& Wilkins. 